\title{
Effect of Shut-in Time on Gas Flow Rate in Hydraulic Fractured Shale Reservoirs
}

\begin{abstract}
Some shale gas and oil wells undergo month-long shut-in times after multi-stage hydraulic fracturing well stimulation. Field data indicate that in some wells, such shut-in episodes surprisingly increase the gas and oil flow rate. In this paper, we report a numerical simulation study that supports such observations and provides a potentially viable underlying imbibition and drainage mechanism. In the simulation, the shale reservoir is represented by a triple-porosity fracture-matrix model, where the fracture forms a continuum of interconnected network created during the well stimulation while the organic and inorganic matrices are embedded in the fracture continuum. The effect of matrix wettability, capillary pressure, relative permeability, and osmotic pressure, that is, chemical potential characteristics are included in the model.
\end{abstract}

The simulation results indicate that the early lower flow rates are the result of obstructed fracture network due to high water saturation. This means that the injected fracturing fluid fills such fractures and blocks early gas or oil flow. Allowing time for the gravity drainage and imbibition of injected fluid in the fracture-matrix network is the key to improving the hydrocarbon flow rate during the shut-in period.

\section{Introduction}

Some shale gas and oil wells undergo month-long shut-in times after multi-stage hydraulic fracture stimulation. Field data indicate that in some wells, such shut-in episodes surprisingly increase the gas and oil flow rate. For example, Fig. 1 shows the effect of an extended shut-in on production of a multi-stage hydraulically fractured well in Marcellus shale (Cheng, 2012). The well was flowed back, after hydraulic fracture stimulation, for a short period before it underwent a six-month shut-in period. When the well was reopened after six months of shut in, gas production rate increased and water production rate decreased significantly. The question is what caused this apparent anomaly?

\section{Water load recovery and flowback behavior}

Field experience indicates that water load recovery could be as low as $5 \%$ of the total injection volume in Haynesville shale to as high as $50 \%$ of that in Barnett and Marcellus shales (King, 2012). Number of mechanisms could contribute to the lowrecovery, including extra-trapped water due to changing in natural fractures width that increasing during injection and decreasing during production periods (Economides et al., 2012), water imbibition into shale matrix by capillary pressure (Cheng, 2012).

Flow back water analyzed by Haluszczak et al. (2013) indicates that formation brine in shale basin could be higher than 150,000 ppm, Fig. 2b. As the typical fracturing fluid comprises low-salinity water, in many cases it is in the range of 1,000 ppm, significant salinity contrast would be expected. This major salinity difference could lead to substantial chemical potential differences creating large osmotic pressure and driving filtrate from natural fractures into shale matrix block.

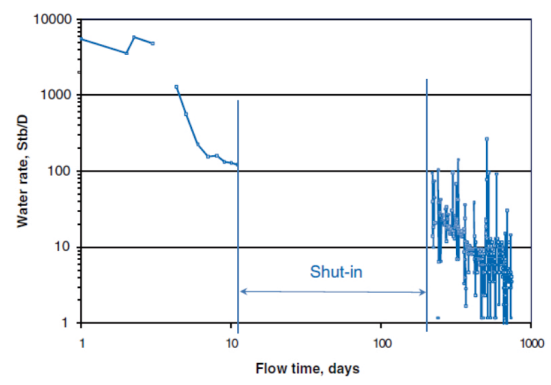

(a)

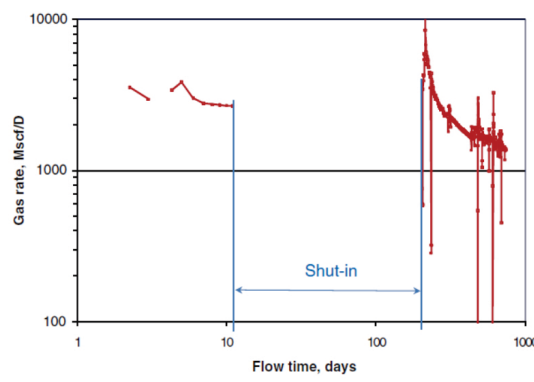

(b)

Fig. 1 - Field production data from a well in Marcellus shale: (a) water production and (b) gas production. After six-month shut-in, gas production increased and water production decreased substantially (Cheng, 2012). 


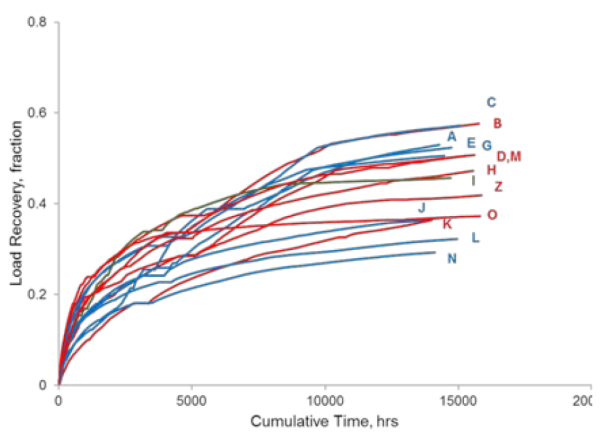

(a)

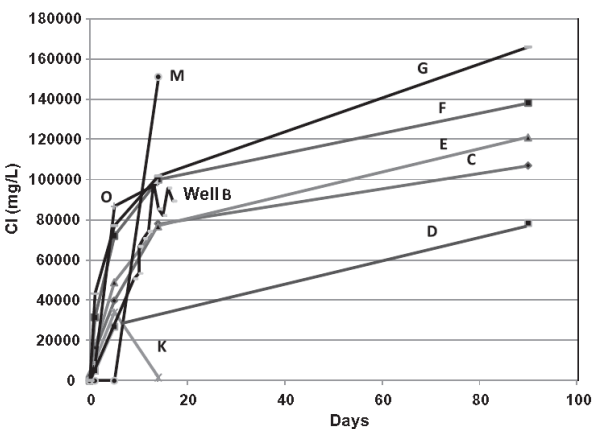

(b)

Fig. 2 - Water load recovery behavior: (a) Load recovery from wells in Horn River shale basin (Economides et al., 2012) and (b) Water salinity profile during flowback and production periods from wells in Marcellus shale basin (Haluszczak et al., 2013).

In this paper, we present the results of a numerical simulation study which replicate similar flow behavior. The reason is that water imbibition into the matrix, augmented by osmotic and capillary pressures, reduces the water saturation while enhancing gas flow into natural fractures to the hydraulic fracture and the wellbore.

\section{Osmotic pressure}

Osmotic pressure is generated by the water concentration gradient across a membrane, which is semi-permeable allowing water molecules but not solution ions flowing through (Neuzil, 2000). Water molecules flow from high-water concentration (low-salinity) to low-water concentration (high-salinity) solutions due to the water concentration gradient until it reaches equilibrium. At the equilibrium, the increase in hydrostatic pressure (p) equals the theoretical osmotic pressure $(\pi)$, Fig. 3.

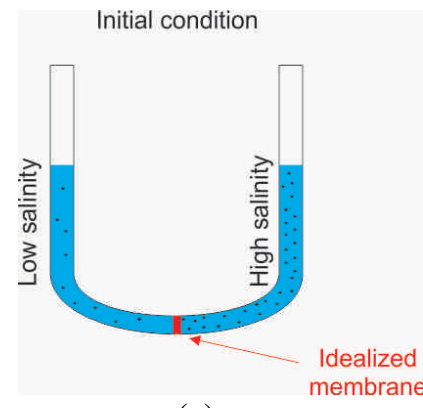

(a)
Equilibrium condition

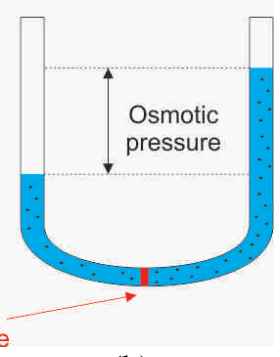

(b)

Fig. 3 - Diagram demonstrating osmotic pressure: (a) At the initial condition and (b) At the equilibrium condition.

In subsurface environment, clay/shale formations could behave as a membrane, where their pore size approaching the thickness of “double layer” clay surface charges (Marine and Fritz, 1981). Marine and Fritz (1981), Neuzil (2000), and Neuzil and Provost (2009) have reported that high pressure anomalies in geological settings could be created by osmotic pressure. Furthermore, high salinity brine in some formations could be explained by reverse osmosis (Bredehoeft et al., 1963). During burial processes, porous rock has been continuously compressed due to the overburden weight increasing. Consequently, the formation brine has been expelled from the formation. Only water molecules could leave as the membrane-like properties of shale prevents salt ions to escape, thus increasing the formation salinity. High-salinity brine in prolific shale formations could be created by the reverse osmotic process, which indicates the membrane-like properties of the shale formations.

Osmotic pressure $(\pi)$, in atm, is described by (Marine and Fritz, 1981):

$$
\pi=\frac{R T}{V} \ln \frac{a_{I}}{a_{I I}}
$$

where,

$a_{I}, a_{I I} \quad$ water activity of system $I$ and $I I$; low-salinity I and high-salinity II, Water activity for fresh water is 1.0 .

$R$

$T$ gas constant, equal to $0.082 \mathrm{~atm} \cdot(\mathrm{g}-\mathrm{mol} \cdot \mathrm{K})^{-1}$

temperature, ${ }^{\circ} \mathrm{K}$

V molar volume, liter/g-mol 
Water activity can be calculated from the Helgeson-Kirkham-Flowers (HKF) equation of state (Helgeson et al., 1981).The calculation of water activity for a high-salinity solution requires an iterative computation procedure (Xu et al., 2012). Thus, we used a chemical reaction simulator (TOUGHREACT) for the calculation. Fig. $\mathbf{4}$ shows the osmotic pressure, created by the salinity difference between formation brine and low-salinity water. The plot is consistent with the calculation by Marine and Fritz (1981). For the typical injected water $(1,000 \mathrm{ppm})$ and formation brine $(150,000 \mathrm{ppm})$ system in shale reservoirs, the osmotic pressure could be as high as 2,000 psi.

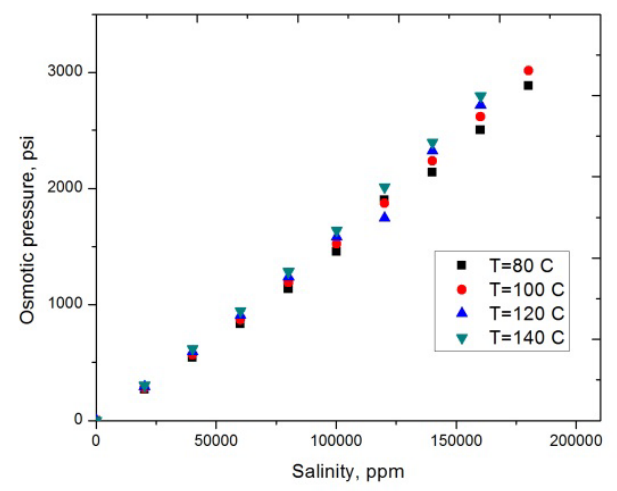

Fig. 4 - Theoretical osmotic pressure created by the salinity difference between formation brine and low-salinity water in fractures at different temperature.

\section{Mathematical model for single phase flow}

For single phase water system, we can include osmotic pressure (Fig. 4) to a fluid flow equation in fractured rock through transfer function $\left(\tau_{\mathrm{f} / \mathrm{m}}\right)$ between fractures and matrix:

$$
\tau_{f / m}=\tau_{f / m}^{p}+\tau_{f / m}^{\pi}=\sigma \frac{k_{m}}{\mu}\left(p_{f}-p_{m}\right)-\sigma E_{o p} \frac{k_{m}}{\mu}\left(\pi_{f}\left(C_{f}\right)-\pi_{m}\left(C_{m}\right)\right)
$$

where,

$C_{f} \quad$ salinity in fracture, $\mathrm{ppm}$

$C_{m} \quad$ salinity in matrix, ppm

$k_{m} \quad$ matrix permeability, $\mathrm{mD}$

$p_{f} \quad$ pressure in fracture, psi

$p_{m} \quad$ pressure in matrix, psi

$\gamma \quad$ fluid gradient, $\mathrm{psi} / \mathrm{ft}$

$\pi_{f} \quad$ osmotic pressure in fracture calculated from salt concentration using Fig. 4, psi

$\pi_{m} \quad$ osmotic pressure in matrix calculated from salt concentration using Fig. 4, psi

$\sigma \quad$ shape factor, $1 / \mathrm{ft}^{2}$

$\tau_{f / m}^{p} \quad$ transfer function caused by pressure, $1 /$ day

$\tau_{f / m}^{\pi} \quad$ transfer function caused by osmotic pressure, $1 /$ day

$E_{\text {op }} \quad$ osmotic pressure efficiency, dimensionless

\section{Pressure equations:}

Fracture:

$$
\nabla \cdot\left(\frac{k_{f, e f f}}{\mu} \nabla p_{f}\right)+\hat{q}-\tau_{f / m}=\left(\phi c_{t}\right)_{f} \frac{\partial p_{f}}{\partial t}
$$

Matrix:

$$
\tau_{f / m}=\left(\phi c_{t}\right)_{m} \frac{\partial p_{m}}{\partial t}
$$

where,

$c_{t} \quad$ total compressibility, 1/psi

$k_{f, e f f} \quad$ effective fracture permeability, md

$\hat{q} \quad$ sink/source term, 1/day

$t \quad$ time, day 
$\phi \quad$ porosity, fraction

$\mu \quad$ fluid viscosity, cp

Salt concentration equations:

In this paper we assumed that salt is not absorbed on the surface of rock grain.

In fracture:

$$
\begin{aligned}
\nabla \cdot\left(C_{f} \frac{k_{f, e f f}}{\mu} \nabla p_{f}\right)+ & C_{f} \hat{q}+C_{f / m}^{p} \tau_{f / m}^{p}+C_{f / m}^{\pi} \tau_{f / m}^{\pi} \\
& \quad-\sigma D_{f / m}\left(C_{f}-C_{m}\right)=\left(C \phi c_{t}\right)_{f} \frac{\partial p_{f}}{\partial t}+\phi_{f} \frac{\partial C_{f}}{\partial t}
\end{aligned}
$$

In matrix:

$$
(C \rho \tau)_{f / m}^{p}+(C \rho \tau)_{f / m}^{\pi}+\sigma D_{f / m}\left(C_{f}-C_{m}\right)=\left(C \phi c_{t}\right)_{m} \frac{\partial p_{m}}{\partial t}+\phi_{m} \frac{\partial C_{m}}{\partial t}
$$

where,
$C_{f}, C_{m}$
salt concentration in fracture and matrix, $\mathrm{M} / \mathrm{M}$
$D_{f / m}$ diffusion coefficient between fracture and matrix, $\mathrm{L}^{2} / \mathrm{T}$
$\sigma$ shape factor, $1 / \mathrm{L}^{2}$

\section{Modeling a Published Osmotic Pressure Experiment}

We matched the results of a chemical osmosis experiment conducted by Takeda et al. (2012) on a siliceous shale sample. The sample, cut from a core taken at depth of $982 \mathrm{~m}$, is $5 \mathrm{~cm}$ in diameter and $1 \mathrm{~cm}$ in thickness. Two reservoirs, filled with sodium chloride solution, were connected to the top and bottom of the sample. The top reservoir contained 0.1 mol/liter salt solution while the bottom reservoir contained $0.55 \mathrm{~mol} /$ liter solution. During the experiment, pressure and salt concentration were measured, which we used for matching with our numerical model. Takeda et al. (2012) report the experimental details.

To simulate the experimental results, we created a 1-D model with seven simulation grids. The first and the last grids

\begin{tabular}{|c|c|c|c|}
\hline & Bottom reservoir & $\underline{\text { Rock }}$ & $\underline{\text { Top reservoirs }}$ \\
\hline \multicolumn{4}{|l|}{ Rock properties } \\
\hline Volume, $\mathrm{ft}^{3}$ & $7.417 \times 10^{-3}$ & $6.923 \times 10^{-3}$ & $3.532 \times 10^{-3}$ \\
\hline Initial pressure, psi & 42.5 & 42.5 & 42.5 \\
\hline Initial concentration, mol/liter & 0.55 & 0.1 & 0.1 \\
\hline Porosity, fraction & & 0.28 & \\
\hline Permeability, mD & & $1.54 \times 10^{-4}$ * & \\
\hline Interface area, $\mathrm{ft}^{2}$ & 0.021 & 0.021 & 0.021 \\
\hline Length, $\mathrm{ft}$ & & 0.032 & \\
\hline Effective diffusion coefficient, $\mathrm{ft}^{2} / \mathrm{day}$ & & $2.487 \times 10^{-5} \star \star$ & \\
\hline Discretization & $1 \times 1 \times 1$ & $5 \times 1 \times 1$ & $1 \times 1 \times 1$ \\
\hline \multicolumn{4}{|l|}{ Matching parameters } \\
\hline Osmotic efficiency, fraction & & 0.05 & \\
\hline
\end{tabular}
represented the bottom and top reservoirs while the shale sample was represented by five simulation girds. Detailed input parameters are shown in Table 1.

The simulation results indicate a good match, Fig. 5. Initially, the pressure in the bottom reservoir sharply increases due to osmotic-induced flow from low-salt concentration to high-salt concentration. As a result, pressure-induced flow takes place. The counter-current flow and diffusion processes decrease salt concentration in the bottom reservoir. In turn, osmotic pressure and pressure in the bottom reservoir decreases. To achieve the matching, the osmotic efficiency of $5 \%$ was used 


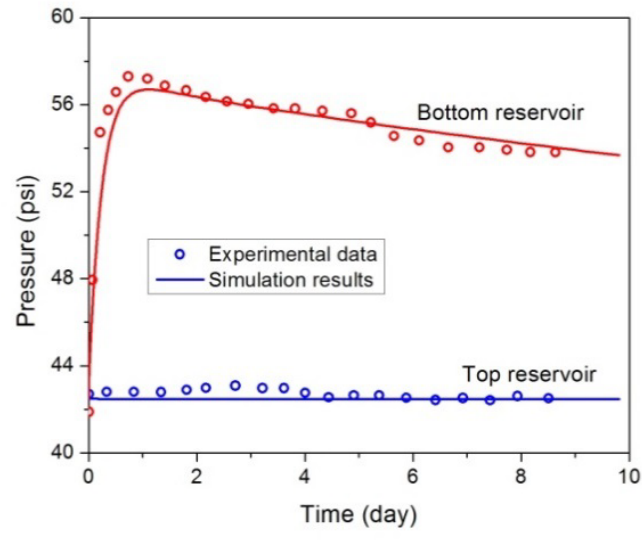

(a)

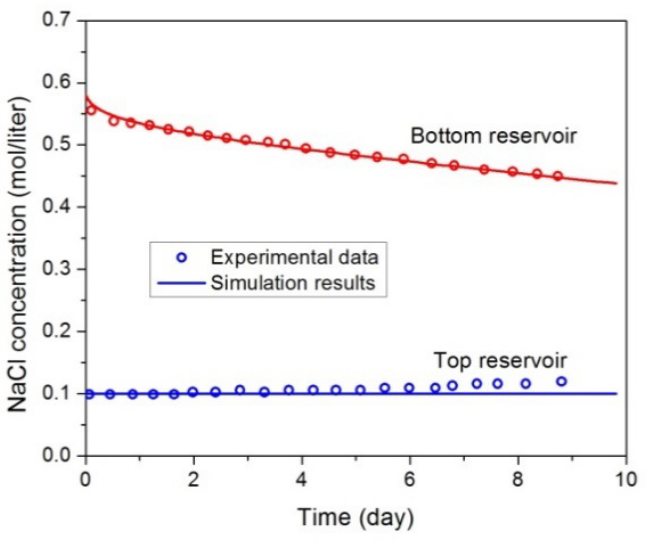

(b)

Fig. 5 - Comparison between experimental data (adopted from Takeda et al., 2012) and simulation results: (a) the pressure profiles in top and bottom reservoirs and (b) the $\mathrm{NaCl}$ concentration in top and bottom reservoirs.

\section{Pore morphology in shale formations and an idealized pore network connection}

Prolific shale formations are often overmature and yield high porosity in organic matter, as high as 50\%, produced from digenesis process (Passey et al., 2010). This type of pore provides storage and connection in organic material, Fig. 6a showing the pore structure in organic matter from a high-resolution scanning-electron microscopy of ion-beam milled Barnett shale sample. Some parts of shale formation can contain inorganic material such as silica grain, quartz, and clay, which are waterwet rocks. These inorganic and organic rocks coexist in shale formations. Thus, we can idealize shale matrix as the combination of organic and inorganic matrix blocks, Fig. 6b. Mathematically, we describe shale pore network as a tripleporosity system including fractures, inorganic, and organic matrices, Fig. 7. Each matrix pore type could connect to natural fractures, which provide high permeability flow path to hydraulic fractures and a wellbore.

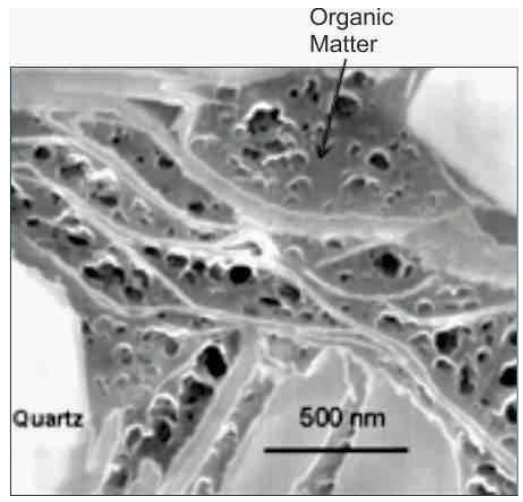

(a)

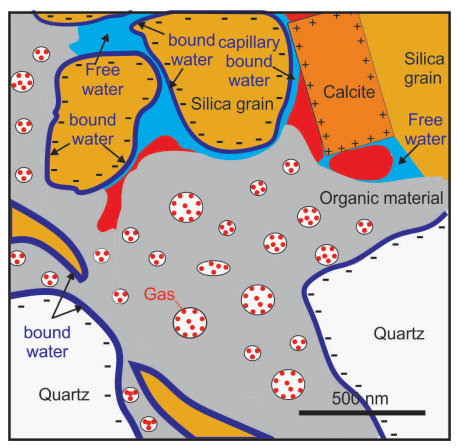

(b)

Fig. 6 - Pore morphology and fluid distribution in shale formations: (a) lon-milled SEM image of a Barnett organic rich shale (Passey et al., 2010), (b) idealized pore network cartoon and fluid content.

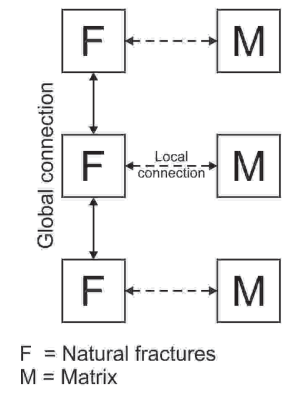

(a)

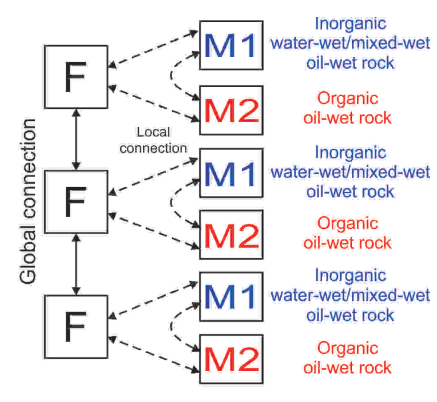

(b)

Fig. 7 - Idealized pore-network connection of fractured rocks: (a) Classical dual-porosity and (b) Triple-porosity for organic-rich shale formations 


\section{Mathematical model for gas-water in triple porosity system}

For mass transfer, we use both osmotic and capillary imbibition. Matrix block is subdivided into inorganic and organic matrices. Inorganics include water-wet silicates, quartz, clays, and calcite. We assumed gas adsorption occurs only on organic material.

\section{Pressure equations:}

Fracture:

Inorganic matrix:

$$
\nabla \cdot k_{f, e f f}\left[\lambda_{t f} \nabla p_{g f}-\left(\lambda_{w f} \gamma_{w}+\lambda_{g f} \gamma_{g}\right) \nabla D\right]+\hat{q}_{t}-\tau_{t, f / m 1}-\tau_{t, f / m 2}=\left(\phi c_{t}\right)_{f} \frac{\partial p_{g f}}{\partial t}
$$

$$
\tau_{t, f / m 1}-\tau_{t, m 1 / m 2}=\left(\phi c_{t}\right)_{m 1} \frac{\partial p_{g m 1}}{\partial t}
$$

Organic matrix:

$$
\tau_{t, f / m 2}+\tau_{t, m 1 / m 2}=\left(\phi c_{t}\right)_{m 2} \frac{\partial p_{g m 2}}{\partial t}+\left(\frac{\rho_{s}\left(V F_{2}-\phi_{m 2}\right) B_{g}}{2200} \frac{a_{\infty} b}{\left(1+b p_{g m 2}\right)^{2}}\right) \frac{\partial p_{g m 2}}{\partial t}
$$

where,

$a_{\infty} \quad$ maximum gas absorption, scf/ton

$b \quad$ Longmuir coefficient, $1 /$ psi

$B_{g} \quad$ gas formation volume factor, $\mathrm{cf} / \mathrm{scf}$

$D \quad$ depth, $\mathrm{ft}$

$p_{g f}, p_{g m 1}, p_{g m 2}$ gas pressure in fracture, inorganic and organic matrices, psi

$\mathrm{VF}_{2} \quad$ volume fraction for organics matrix

$\gamma_{g}, \gamma_{w} \quad$ gas and water gradient, $\mathrm{psi} / \mathrm{ft}$

$\lambda_{g}, \lambda_{w}, \lambda_{t} \quad$ gas, water, and total mobility, $1 / \mathrm{cp}$

$\rho_{\mathrm{s}} \quad$ rock density, $\mathrm{lb} / \mathrm{ft}^{3}$

$\tau_{t f / m 1}, \tau_{t f / m 2} \quad$ total transfer function between fracture and iorganic, and fracture and organic rocks, 1/day, defined as follow:

Fracture (f) - inorganic matrix (m1) connection:

$$
\begin{gathered}
\tau_{t, f / m 1}=\tau_{w, f / m 1}^{p}+\tau_{w, f / m 1}^{\pi}+\tau_{g, f / m 1} \\
\tau_{w, f / m 1}^{p}=\sigma_{f / m 1} k_{m} \lambda_{w f / m 1}\left[\left(p_{g f}-p_{g m 1}\right)-\left(p_{c g w f}-p_{c g w m 1}\right)+\frac{\sigma_{z, f / m 1}}{\sigma_{f / m 1}} \gamma_{w}\left(h_{w f}-h_{w m 1}\right)\right] \\
\tau_{g, f / m 1}=\sigma_{f / m 1} k_{m} \lambda_{g f / m 1}\left[\left(p_{g f}-p_{g m 1}\right)-\frac{\sigma_{z, f / m 1}}{\sigma_{f / m 1}} \gamma_{g}\left(h_{w f}-h_{w m 1}\right)\right] \\
\tau_{w, f / m 1}^{\pi}=-\sigma_{f / m 1} k_{m} \lambda_{w f / m 1} E_{o p}\left(\pi_{f}\left(C_{f}\right)-\pi_{m 1}\left(C_{m 1}\right)\right)
\end{gathered}
$$

Fracture (f) - organic matrix (m2) connection:

$$
\begin{gathered}
\tau_{t, f / m 2}=\tau_{w, f / m 2}^{p}+\tau_{w, f / m 2}^{\pi}+\tau_{g, f / m 2} \\
\tau_{w, f / m 2}^{p}=\sigma_{f / m 2} k_{m} \lambda_{w f / m 2}\left[\left(p_{g f}-p_{g m 2}\right)-\left(p_{c g w f}-p_{c g w m 2}\right)+\frac{\sigma_{z, f / m 2}}{\sigma_{f / m 2}} \gamma_{w}\left(h_{w f}-h_{w m 2}\right)\right] \\
\tau_{g, f / m 2}=\sigma_{f / m 2} k_{m} \lambda_{g f / m 2}\left[\left(p_{g f}-p_{g m 2}\right)-\frac{\sigma_{z, f / m 2}}{\sigma_{f / m 2}} \gamma_{g}\left(h_{w f}-h_{w m 2}\right)\right] \\
\tau_{w, f / m 2}^{\pi}=-\sigma_{f / m 2} k_{m} \lambda_{w f / m 2} E_{o p}\left(\pi_{f}\left(C_{f}\right)-\pi_{m 2}\left(C_{m 2}\right)\right)
\end{gathered}
$$

Inorganic matrix (m1) - organic matrix (m2) connection:

$$
\begin{gathered}
\tau_{t, m 1 / m 2}=\tau_{w, m 1 / m 2}^{p}+\tau_{w, m 1 / m 2}^{\pi}+\tau_{g, m 1 / m 2} \\
\tau_{w, m 1 / m 2}^{p}=\sigma_{m 1 / m 2} k_{m} \lambda_{w, m 1 / m 2}\left[\left(p_{g m 1}-p_{g m 2}\right)-\left(p_{c g w m 1}-p_{c g w m 2}\right)+\frac{\sigma_{z, m 1 / m 2}}{\sigma_{m 1 / m 2}} \gamma_{w}\left(h_{w m 1}-h_{w m 2}\right)\right]
\end{gathered}
$$




$$
\begin{aligned}
& \tau_{g, m 1 / m 2}=\sigma_{m 1 / m 2} k_{m} \lambda_{g, m 1 / m 2}\left[\left(p_{g m 1}-p_{g m 2}\right)-\frac{\sigma_{z, m 1 / m 2}}{\sigma_{m 1 / m 2}} \gamma_{g}\left(h_{w m 1}-h_{w m 2}\right)\right] \\
& \tau_{w, m 1 / m 2}^{\pi}=-\sigma_{m 1 / m 2} k_{m} \lambda_{w, m 1 / m 2} E_{o p}\left(\pi_{m 1}\left(C_{m 1}\right)-\pi_{m 2}\left(C_{m 2}\right)\right)
\end{aligned}
$$

where,

$\tau^{p}, \tau^{\pi}$

$\sigma_{m 1 / m 2}, \sigma_{z, m 1 / m 2}$

transfer function induced by pressure and osmotic pressure, 1/day

direction only, $1 /$ day

$h_{w m 1}, h_{w m 2} \quad$ equivalent water column height in inorganic and organic matrices, $\mathrm{ft}$

$E_{\text {op }} \quad$ osmotic pressure efficiency, dimensionless

\section{Saturation equations:}

\section{Fracture:}

Inorganic matrix:

$$
\begin{aligned}
\nabla \cdot k_{f, e f f}\left[\lambda_{w f} \nabla p_{g f}-\lambda_{w f} \gamma_{w} \nabla D\right] & +\hat{q}_{w} \\
& \quad-\tau_{w, f / m 1}-\tau_{w, f / m 2}=\phi_{f} S_{w f}\left(c_{\phi f}+c_{w}\right) \frac{\partial p_{g f}}{\partial t}+\phi_{f} \frac{\partial S_{w f}}{\partial t}
\end{aligned}
$$

Organic matrix:

$$
\tau_{w, f / m 1}-\tau_{w, m 1 / m 2}=\phi_{m 1} S_{w m 1}\left(c_{\phi m}+c_{w}\right) \frac{\partial p_{g m 1}}{\partial t}+\phi_{m 1} \frac{\partial S_{w m 1}}{\partial t}
$$

$$
\tau_{w, f / m 2}+\tau_{w, m 1 / m 2}=\phi_{m 2} S_{w m 2}\left(c_{\phi m}+c_{w}\right) \frac{\partial p_{g m 2}}{\partial t}+\phi_{m 2} \frac{\partial S_{w m 2}}{\partial t}
$$

\section{Salt concentration equations:}

Fracture:

$$
\begin{aligned}
& \nabla \cdot C_{f} k_{f, e f f}\left[\lambda_{w f} \nabla p_{g f}-\lambda_{w f} \gamma_{w} \nabla D\right]+C_{f} \hat{q}_{w}-C_{f / m 1, p} \tau_{w, f / m 1, p} \\
& +C_{f / m 1, \pi} \tau_{w, f / m 1, \pi}-\sigma_{f / m 1} D_{f / m 1}\left(C_{f}-C_{m 1}\right)-C_{f / m 2, p} \tau_{w, f / m 2, p}+C_{f / m 2, \pi} \tau_{w, f / m 2, \pi} \\
& \quad-\sigma_{f / m 2} D_{f / m 2}\left(C_{f}-C_{m 2}\right)=C_{f} \phi_{f} S_{w f}\left(c_{\phi f}+c_{w}\right) \frac{\partial p_{g f}}{\partial t}+C_{f} \phi_{f} \frac{\partial S_{w f}}{\partial t}+\phi_{f} S_{w f} \frac{\partial C_{f}}{\partial t}
\end{aligned}
$$

Inorganic matrix:

Organic matrix:

$$
\begin{aligned}
& C_{f / m 1, p} \tau_{w, f / m 1, p}-C_{f / m 1, \pi} \tau_{w, f / m 1, \pi}+\sigma_{f / m 1} D_{f / m 1}\left(C_{f}-C_{m 1}\right) \\
& -C_{m 1 / m 2, p} \tau_{w, m 1 / m 2, p}+C_{m 1 / m 2, \pi} \tau_{w, m 1 / m 2, \pi}-\sigma_{m 1 / m 2} D_{m 1 / m 2}\left(C_{m 1}-C_{m f}\right) \\
& =C_{m 1} \phi_{m 1} S_{w m 1}\left(c_{\phi m}+c_{w}\right) \frac{\partial p_{g m 1}}{\partial t}+C_{m 1} \phi_{m 1} \frac{\partial S_{w m 1}}{\partial t}+\phi_{m 1} S_{w m 1} \frac{\partial C_{m 1}}{\partial t}
\end{aligned}
$$

where,

$$
\begin{aligned}
& C_{f / m 2, p} \tau_{w, f / m 2, p}-C_{f / m 2, \pi} \tau_{w, f / m 2, \pi}+\sigma_{f / m 2} D_{f / m 2}\left(C_{f}-C_{m 2}\right) \\
& +C_{m 1 / m 2, p} \tau_{w, m 1 / m 2, p}-C_{m 1 / m 2, \pi} \tau_{w, m 1 / m 2, \pi}+\sigma_{m 1 / m 2} D_{m 1 / m 2}\left(C_{m 1}-C_{m f}\right) \\
& =C_{m 2} \phi_{m 2} S_{w m 2}\left(c_{\phi m}+c_{w}\right) \frac{\partial p_{g m 2}}{\partial t}+C_{m 2} \phi_{m 2} \frac{\partial S_{w m 2}}{\partial t}+\phi_{m 2} S_{w m 2} \frac{\partial C_{m 2}}{\partial t}
\end{aligned}
$$

$C_{f}, C_{m 1}, C_{m 2} \quad$ Salt concentration in fracture, inorganic and organic matrices, ppm

$\tau_{w f / m 1}, \tau_{w f / m 2} \quad$ water transfer function between fracture and inorganic, and fracture and organic rocks, 1/day, defined in Eq. $10-$ Eq. 12 


\section{Numerical simulation study}

A 2-D sector model was constructed to represent a section covers one bi-wing hydraulic fracture, Fig. 8. The shale reservoir is represented by a triple-porosity fracture-matrix model, where the fracture forms a continuum of interconnected network created during the well simulation while the organic and inorganic matrices are embedded in the fracture continuum. Explicit orthogonal grids are assigned as a static hydraulic fracture with the dimensionless fracture conductivity of 10. Logarithmic grid size distribution near the hydraulic fracture is used to capture flow behavior near the fracture. No fracture propagation was modeled. Detailed reservoirs and hydraulic fracture input data can be found in Table 2 and Fig. 9.

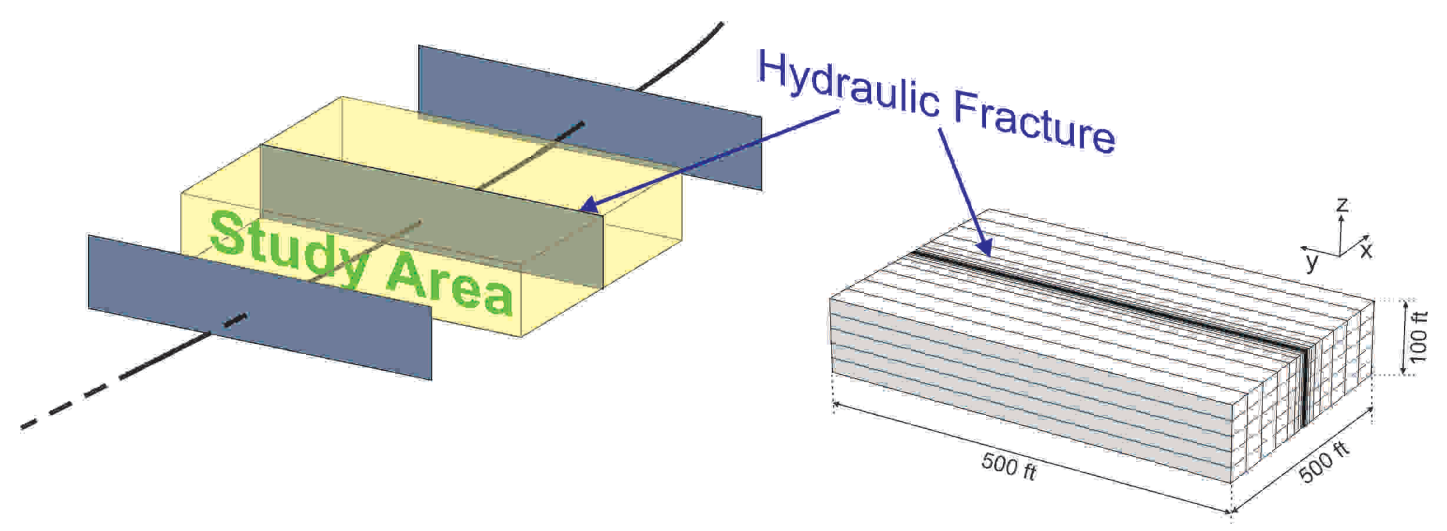

Fig. 8 - Model schematic: a 2-D sector model

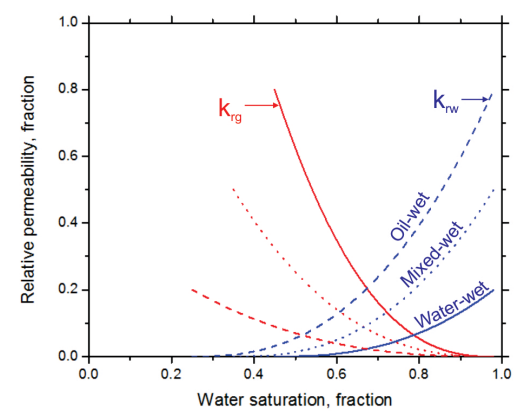

(a)

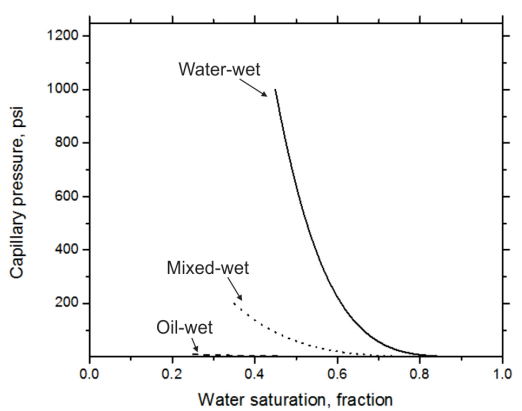

(b)

Fig. 9 -Rock properties: (a) relative permeability and (b) capillary pressure. 


\begin{tabular}{|c|c|c|c|}
\hline \multicolumn{4}{|c|}{ TABLE 2 - INPUT PARAMETERS FOR BASE CASE RUN } \\
\hline Parameter & Natural fractures (f) & Inorganic rock $\left(\mathrm{m}_{1}\right)$ & Organic rock $\left(m_{2}\right)$ \\
\hline Effective permeability, md & 0.01 & 0.0001 & 0.0001 \\
\hline Effective porosity, fraction & 0.002 & 0.054 & 0.030 \\
\hline Irreducible water saturation, fraction & 0.05 & $\begin{array}{c}0.40 \text { (water-wet) } \\
0.35 \text { (mixed-wet) } \\
0.25 \text { (oil-wet) }\end{array}$ & 0.25 (oil-wet) \\
\hline $\begin{array}{l}\text { Capillary pressure at irreducible } \\
\text { water saturation, psi }\end{array}$ & 1.0 & $\begin{array}{l}1000.0 \text { (water-wet) } \\
200.0 \text { (mixed-wet) } \\
10.0 \text { (oil-wet) }\end{array}$ & 10.0 \\
\hline Volume fraction, fraction & - & 0.9 & 0.1 \\
\hline Shape factor, $1 / \mathrm{ft}^{2}$ & $0.30\left(f-m_{1}\right)$ & $0.10\left(m_{1}-m_{2}\right)$ & $0.03\left(f-m_{2}\right)$ \\
\hline Salt diffusion coefficient, $\mathrm{ft}^{2} / \mathrm{day}$ & $10^{-8}\left(f-m_{1}\right)$ & $10^{-8}\left(\mathrm{~m} 1-\mathrm{m}_{2}\right)$ & $10^{-8}\left(f-m_{2}\right)$ \\
\hline Formation brine salinity, ppm & 150,000 & 150,000 & 150,000 \\
\hline Osmotic pressure coefficient & & 0.1 & 0.1 \\
\hline $\begin{array}{l}\text { Gas absorption coefficient } \\
\text { Maximum gas absorption, scf/ton } \\
\text { Longmuir coefficient, } 1 / p s i\end{array}$ & $\mathrm{n} / \mathrm{a}$ & $\mathrm{n} / \mathrm{a}$ & $\begin{array}{c}2000^{*} \\
0.00044\end{array}$ \\
\hline
\end{tabular}

* Higher than a typical value because it only applies to the organic rock volume while the typical value is the weighted average absorption value for whole rocks including inorganic rock.

\section{Model Initialization}

The simulation was initialized by injecting 5,000 bbl of fracturing fluid, which has salinity of 1,000 ppm into the model to create the post-fracturing water saturation and salinity distributions near the hydraulic fracture. The water saturation and salinity profiles in the fracture network after the injection is shown in Fig. 10.
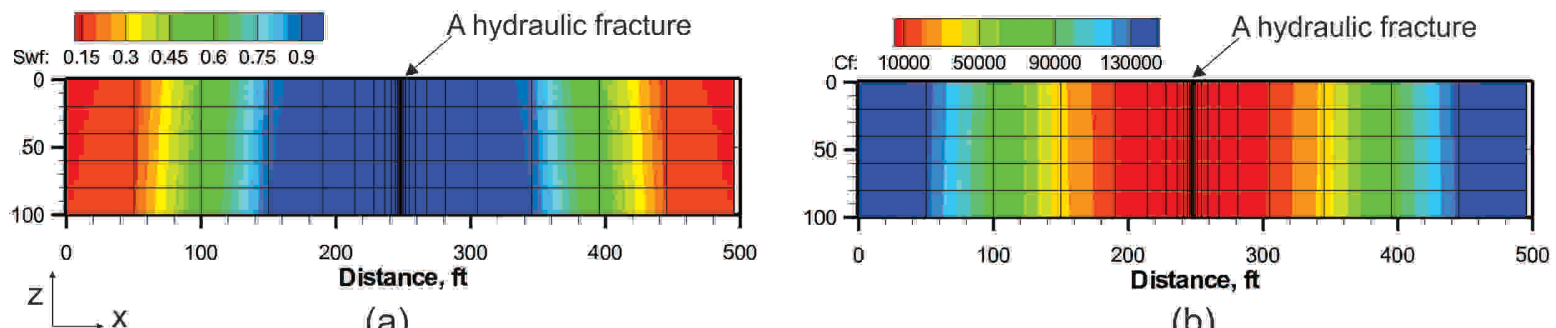

(b)

Fig. 10 - The condition after 5,000 bbl of fracturing fluid is injected into the model: (a) water saturation and (b) salinity profiles

\section{Simulation cases}

The simulation cases were designed to evaluate the impact of various contributing mechanisms during shut-in and production periods. These mechanisms include the effects of rock wettability, gravity, capillarity, osmoticity, and capillary end. Table 3 presents the simulation cases. Every case was run with 0-day, 7-day, 15-day, and 30-day shut-in periods.

Case 1: Wettability effect

Mineral composition of shale can vary significantly even within the same basin. For example, Barnett shale can have quartz (water-wet) dominant rock composition in one area and carbonate (oil-wet) dominant rock composition in another area, Passey et al. (2010). As a result, rock wettability also varies. This numerical experiment was conducted to investigate the impact of rock wettability in inorganic portion of shale rocks. Water-wet, mixed-wet, and oil-wet rocks were included. The wettability variation was modeled by using different sets of capillary and relative permeability. As there is no credible capillary and relative permeability for shale formations available, synthetic data was used (Fig. 9).

Case 2: Gravity, capillarity, and osmoticity effects

This numerical experiment was conducted to investigate the contribution of gravity, capillary, and osmoticity on the filtrate imbibition to shale matrix. The simulation was conducted by turn on each mechanism for its simulation run. 


\begin{tabular}{|c|c|c|c|}
\hline \multicolumn{4}{|c|}{ TABLE 3 -SIMULATION CASES } \\
\hline Case & Description & Feature & Remark \\
\hline $\begin{array}{l}1.1 \\
1.2 \\
1.3\end{array}$ & Wettability effects & $\begin{array}{l}\text { Water-wet } \\
\text { Mixed-wet } \\
\text { Oil-wet }\end{array}$ & $\begin{array}{l}\text { No osmotic effect } \\
\text { No osmotic effect } \\
\text { No osmotic effect }\end{array}$ \\
\hline $\begin{array}{l}2.1 \\
2.2 \\
2.3 \\
2.4 \\
2.5\end{array}$ & Gravity, Capillary, and osmotic effects & $\begin{array}{l}\text { Gravity effect } \\
\text { Capillary effect } \\
\text { Osmotic effect } \\
\text { Combined effect }\end{array}$ & $\begin{array}{l}\text { No gravity, capillary and osmotic effects } \\
\text { No capillary and osmotic effects } \\
\text { No gravity and osmotic effects } \\
\text { No gravity and capillary effects } \\
\text { - }\end{array}$ \\
\hline $\begin{array}{l}3.1 \\
3.2 \\
3.3\end{array}$ & Osmotic efficiency effects & $\begin{array}{l}\text { Efficiency }=100 \% \\
\text { Efficiency }=10 \% \\
\text { Efficiency }=1 \%\end{array}$ & \\
\hline
\end{tabular}

Case 3: Osmotic efficiency effect

The significant salinity contrast between the fracturing filtrate fluid in fractures and formation brine in shale matrix can induce large osmotic pressure. Ideal osmotic pressure can be calculated from chemical potential of the salinity contrast, discussed in the previous section. However, osmotic efficiency depends on rock properties which can vary from one shale basin to another. As experimental data for the efficiency in multi-phase system is not available, this case was designed to theoretical investigate the effect of the efficiency. Three simulation cases with the efficiency of $11 \%, 10 \backslash \%$, and $100 \backslash \%$ were run.

\section{Simulation results}

This section presents the simulation results. The simulation results of the study for effects of well shut-in on shale gas production are discussed as follows:

\section{Water saturation during shut-in period}

The water saturation profiles in the fracture network during the well shut-in after the hydraulic fracturing treatment for waterwet (Case 1.1), mixed-wet (Case 1.2), and oil-wet (Case 1.3) rocks are shown in Fig. 11. At the beginning, the fracturing fluid filtrate occupies majority of the pore space inside the fractures. The shut-in period allows the combination of gravity and capillarity to imbibe the filtrate. Water-wet rock exhibits strong capillarity, which helps imbibe the filtrate while mixed-wet rock has intermediate capillary pressure that slowly imbibes the filtrate. The longer the shut-in period the more the filtrate is imbibed into the shale matrix. As a result, the water saturation in the fractures decreases with shut-in time. However, oil-wet rock which has minimal capillary force can barely imbibe the filtrate. Thus, most of the filtrate is still inside the fractures. 
Water-wet rock

\section{Right after} stimulation

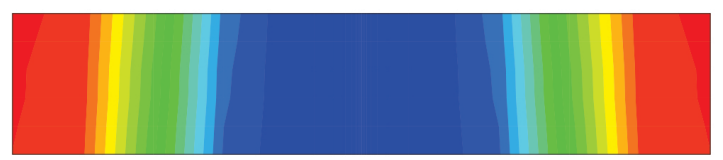

(a)

After 7 days shut-in

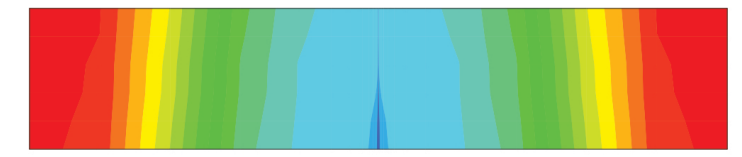

(b)

After 15 days shut-in

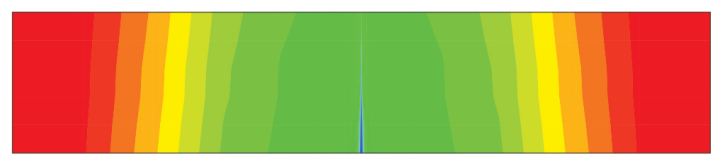

(c)

After 30 days shut-in

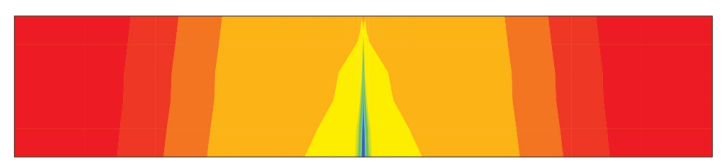

(d)
Mixed-wet rock

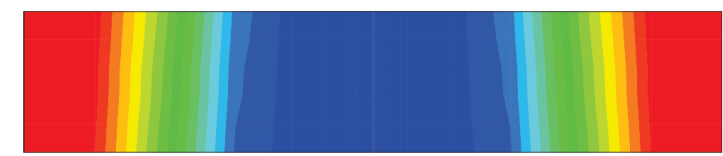

(e)

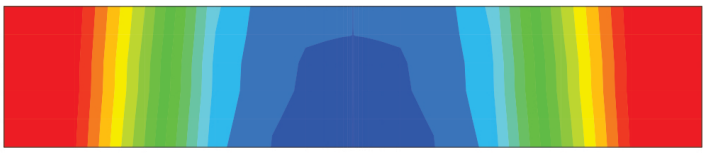

(f)

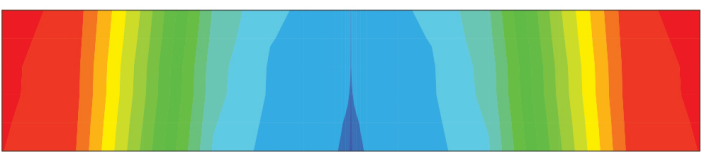

(g)

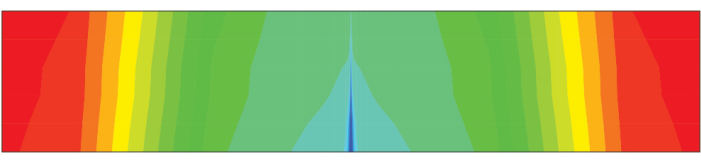

(h)

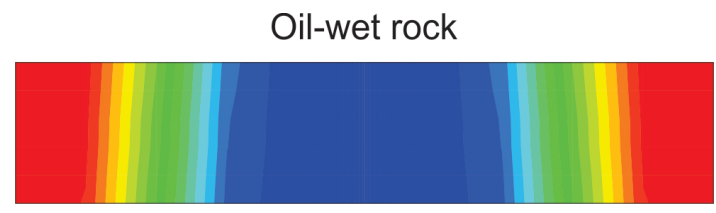

(j)

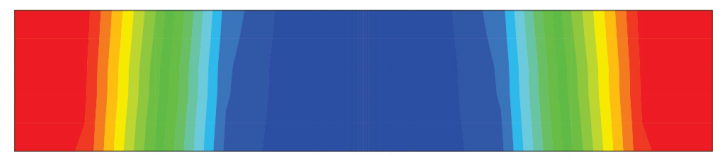

(k)

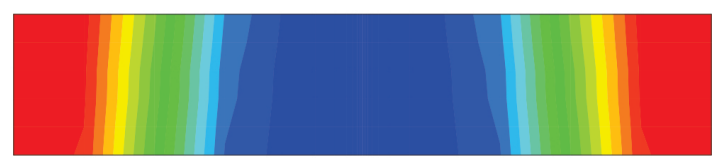

(I)

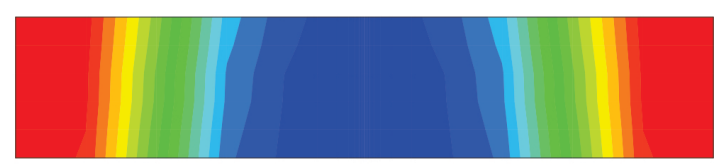

(m)

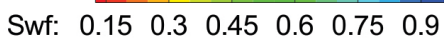

Fig. 11 - Water saturation profiles in fractures for: Water-wet rocks after (a) 0-day shut-in, (b) 7-day shut-in, (c) 15-day shut-in, and (d) 30-day shut-in, mixed-wet rocks after (e) 0-day shut-in, (f) 7-day shut-in, (g) 15-day shut-in, and (h) 30-day shut-in, and oil-wet rocks after (j) 0-day shut-in, (k) 7-day shut-in, (l) 15-day shut-in, and (m) 30-day shut-in. For water-wet rocks, highcapillary pressure helps imbibe the filtrate, which rapidly reduces the water saturation inside the fractures. Mixed-wet rocks have intermediate capillary pressure, which helps imbibe the filtrate with slower rate than that of the water-wet rocks. Finally, oil-wet rocks do not imbibe the filtrate, thus staying inside the fractures. 
Gas production

The effects of long shut-in period on gas flow rate and cumulative production for the base case run are shown in Fig 12. As discussed in the previous section, shut-in period allows the shale matrix adjacent to the fractures to imbibe the filtrate, which reduces the water saturation inside the fracture. As a result, once the well is put on production, the gas flow rate increases. The effects do not last very long. The rate decreases to a stabilized rate within about a month; and the well shut-in does not affect the cumulative gas production. Further investigation on long term gas production is required to include long term impairment during water imbibition process e.g. relative permeability hysteresis, shale swelling, which is not included in this study.

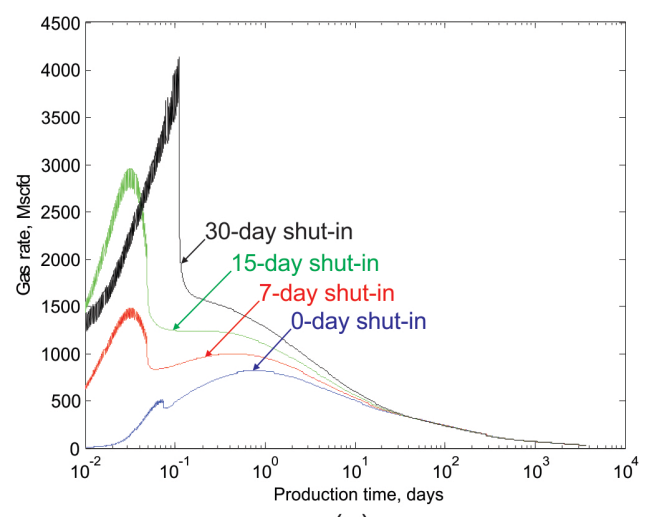

(a)

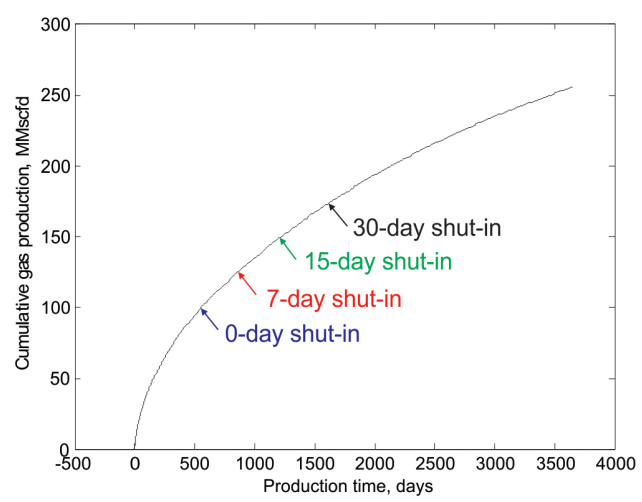

(b)

Fig. 12 - Gas production profiles for the base case (Case 2.4) with 0-day shut-in, 7-day shut-in, 15 shut-in, and 30-day shut-in: (a) gas production rate and (b) cumulative gas production.

\section{Water production}

Unlike gas production, water flow rate decreases when the well is shut-in for long period, Fig. 13. This is because the longer the shut-in, the more the fracturing fluid filtrate is imbibed into shale matrix. Thus, the production rate and cumulative water production are decreased. In the base case with mixed-wet inorganic matrix, a month shut-in time reduces the load water recovery from $\sim 50 \%$ to $\sim 20 \%$ of the total injection volume.

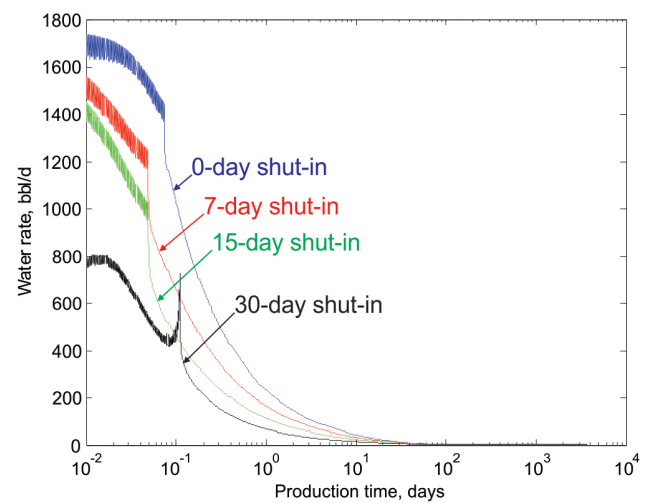

(a)

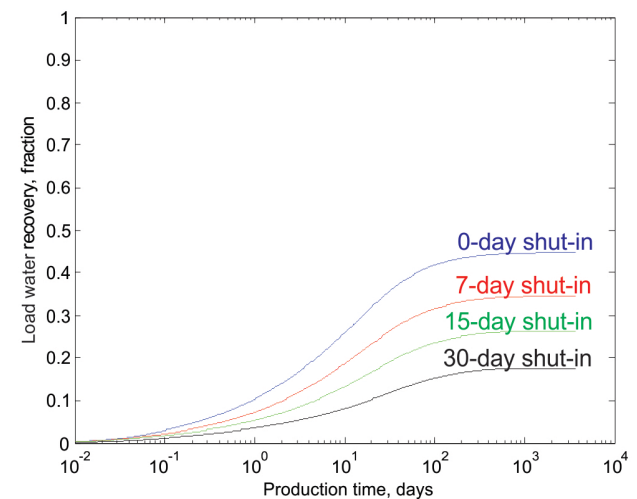

(b)

Fig. 13 - Water production profiles for the base case (Case 2.4) with 0-day shut-in, 7-day shut-in, 15 shut-in, and 30-day shut-in: (a) water production rate and (b) load water recovery (cumulative water production/total water injection).

\section{Salinity of produced water}

The salinity profiles shown in Fig. 14 indicate the increasing produced water salinity. This is because at the beginning the produced water comprises mainly the injected fluid which contains low-salinity water as the injected fluid flushes the formation brine inside the fractures away from the hydraulic fracture. Later, the formation fluid flows to the well and mixes with the injected water, thus increasing the produced water salinity. A mixing process occurs during the shut-in period and causes the slight increase in the salinity of produced water at the beginning of the production period after well shut-in.

\section{Effects of wettability}

Wettability has a significant impact on shale matrix imbibition. High-capillary pressure in water-wet rocks imbibes the filtrate into shale matrix and reduces the water saturation in the fractures, during the well shut-in. As a result, the gas flow rate increases, Fig. 15. On the other hand, oil-wet rocks cannot imbibe the filtrate. Thus, water saturation in the fractures is still high even after 30-day shut-in and no gas flow rate improvement is observed. 


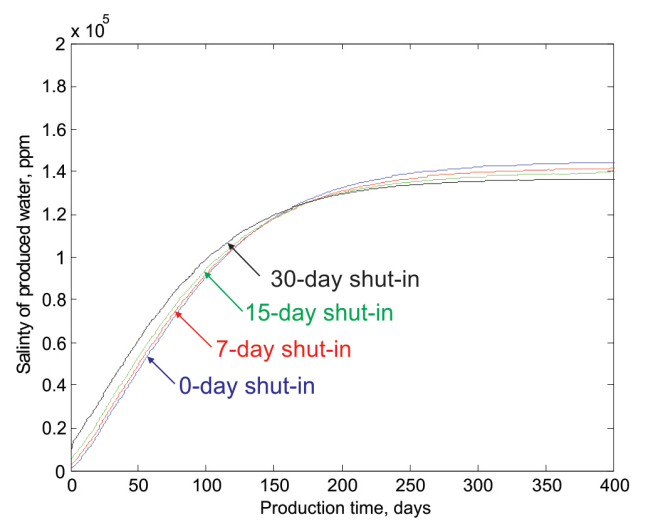

Fig 14 - salinity of produced water for the base case (Case 2.4) with 0-day shut-in, 7-day shut-in, 15 shut-in, and 30-day shut-in.

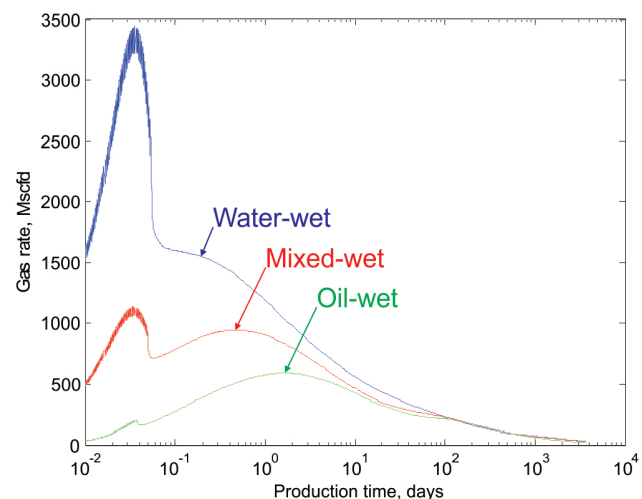

(a)

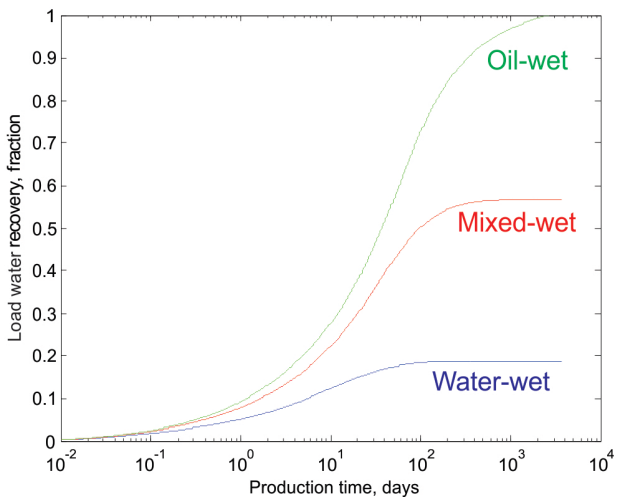

(b)

Fig. 15 - Production profiles with 15-day shut-in for water-wet, mixed-wet, and oil-wet rocks: (a) gas production rate and (b) load water recovery.

Effects of gravity, capillarity, and osmoticity

Fig. 16 shows the separated effects of gravity, capillarity and osmoticity on gas flow-rate and load water recovery with 15-day shut-in period in mixed-wet rocks. Osmoticity and capillarity have positive effects on the gas production and also reduces the load water recovery. This, in turn, indicates that both forces induce more filtrate to enter the shale matrix as discussed in the previous sections. Osmotic effect seems to have more significant effect than that of capillarity; but, gravity has minimal effect on both the gas flow rate and the load water recovery.

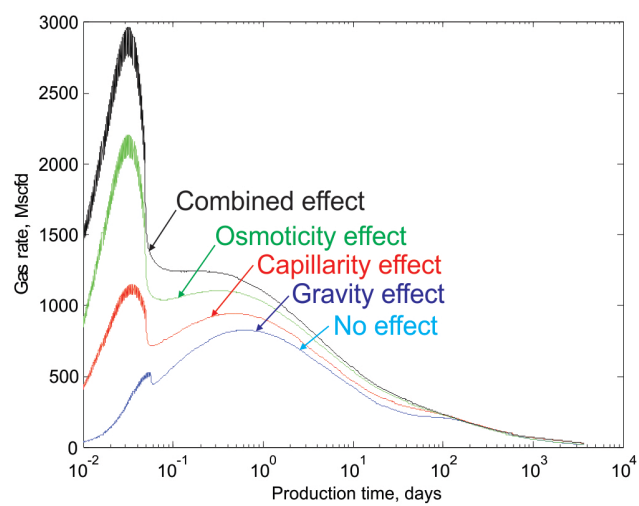

(a)

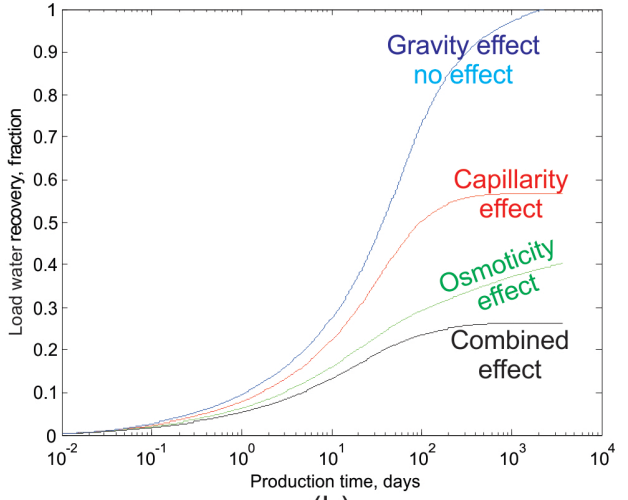

(b)

Fig 16 - Production profiles in mixed-wet rocks, with 15-day shut-in for separated effect of gravity, capillarity, and osmoticity: (a) gas production rate and (b) load water recovery.

Effects of osmotic pressure in water- and oil-wet rocks

The effects of osmoticity in water-wet and oil-wet rocks on gas flow rate are plotted in Fig. 17. In both cases, osmotic pressure improves gas flow rate after well shut-in. This is because osmotic pressure is induced by salinity contrast between the fractures and the shale matrix. Thus, wettability does not impact the fracture-matrix mass transfer induced by the pressure. 


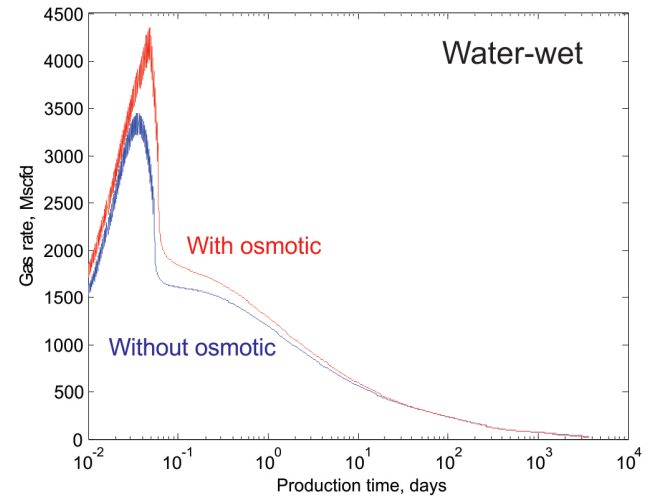

(a)

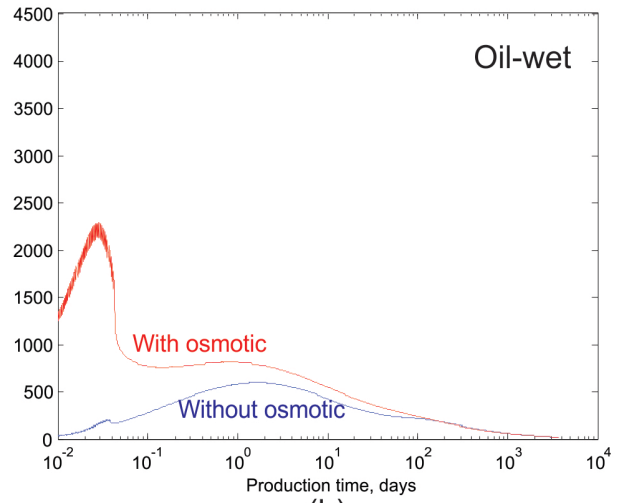

(b)

Fig. 17 - Comparison of gas flow rate profiles between with and without osmotic effect with 15-day shut-in for: (a) water-wet and (b) oil-wet rocks.

\section{Effects of osmotic efficiency}

Fig. 18 shows the effects of osmotic efficiency on gas flow rate and load water recovery after 15-day shut-in. Increasing the osmotic efficiency helps improve gas flow rate after shut-in as it magnifies the effect of osmotic pressure. The minimal osmotic effect is shown with $11 \%$ efficiency.

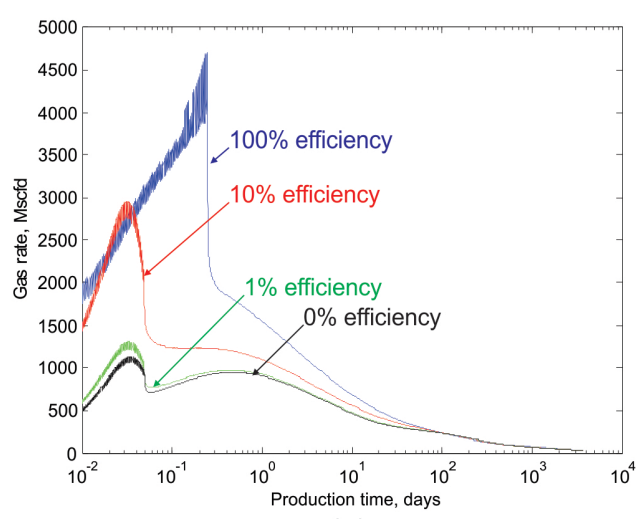

(a)

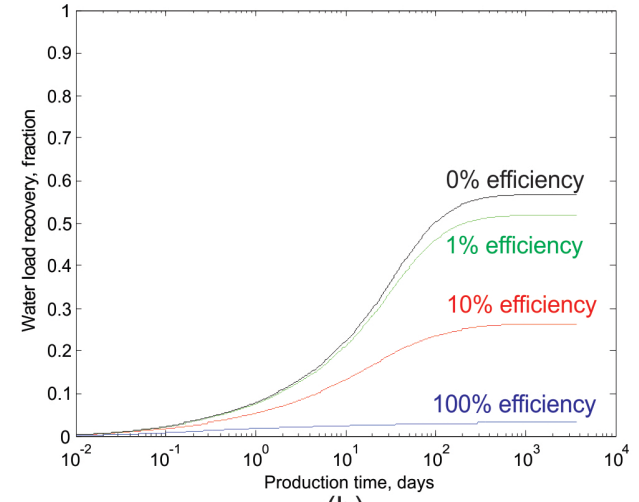

(b)

Fig 18 - Production profiles in mixed-wet rocks, with 15-day shut-in for various osmotic efficiencies: (a) gas flow rate and (b) load water recovery.

\section{Discussions}

The simulation results replicate the field observation (Fig 12 - 14) and provide the physical mechanisms controlling gas and water flow rates after well shut-in. This simulation is performed under the assumption that no fluid rock chemical interaction. In high-smectite formations, clay swelling effect could cause damage by reducing fracture permeability. In practice, some surfactants are added to avoid the damage.

\section{Effects of well shut-In}

During hydraulic fracture stimulation, fracturing fluid injected into shale formations can occupy pore space inside the natural fractures and block the fluid flow paths. These fractures are vital to production in providing high-permeability flow paths from the tight shale matrix into microfractures, hydraulic fractures and eventually into the wellbore.

Well shut-in after a hydraulic fracturing treatment can increase gas and reduce water flow rates if (1) the inorganic shale matrix is water-wet or mixed-wet rock or (2) osmotic efficiency is more than $11 \%$. This is because capillary pressure (positive value in water-wet and mixed-wet rocks) and osmotic pressure help imbibe the fracturing fluid filtrate into shale matrix, thus reducing water and increasing gas saturations in the fractures which leads to higher gas and lower water flow rates. The effect on gas flow rate only last for about a month without impact on the long-term production. On the other hand, the shut-in will not affect gas and water flow rates if the inorganic shale matrix is oil-wet rock and osmotic efficiency is lower than $1 \%$. 
Rock wettability plays an important role controlling water imbibition. Water-wet and mixed-wet rocks have positive capillary pressure which can induce water imbibition from the fractures to shale matrix, thus reducing water saturation inside the fractures. In contrast, zero or negative capillary pressure in oil-wet rock does not imbibe water. As a result, the filtrate stays inside the fractures.

\section{Effects of osmotic pressure}

The effects of osmotic pressure on gas and water flow rates after well shut-in is demonstrated in Fig. 16 and 18 . The pressure can induce the flow of low-salinity fracturing fluid inside the fractures into the shale matrix containing high-salinity formation brine. The effect takes place not only in the water-wet but also in the oil-wet rocks where water is not imbibed by capillary force, Fig. 17.

However, the observed increase in gas flow rate can be satisfactorily explained by the variation in the rock wettability and capillary pressure without osmotic pressure; and osmotic efficiency in multi-phase systems is not well-understood as no experimental data is available. Thus, experiments to measure osmotic pressure and efficiency in multi-phase systems, shale formations are required to confirm the findings.

\section{Conclusions}

In this paper, we report the development of a mathematical model to include gravity, capillary, and osmotic pressure effects in a triple-porosity system for organic-rich shale formations. We conducted the numerical experiments to investigate the effect of the post-fracturing long shut-in periods on the initial gas production rate and fracturing fluid recovery. The following conclusion can be drawn from the simulation results:

1. We have been able to simulate the effect of shut-in of newly created hydraulic fractures on increased production of gas in organic-rich shale reservoirs. The results are similar with field data reported in literature.

2. Well shut-in after a hydraulic fracturing treatment can increase gas and reduce water flow rates if (1) the inorganic shale matrix is water-wet or mixed-wet rock or (2) osmotic efficiency is more than $1 \%$. However, the effects do not last very long and may not impact long-term production.

3. Capillary and osmotic pressures cause the fracturing fluid filtrate to enter shale matrix during the well shut-in. As a result, the water saturation in the fractures becomes smaller which increases gas flow rate.

4. The effect of osmotic pressure on accelerating fracture-matrix mass transfer takes place not only in the water-wet but also in the oil-wet rocks, where water is not imbibed by capillary force.

5. Gravity has minimal effect on the filtrate imbibition during the well shut-in because natural fractures and shale matrix are very tight.

\section{Acknowledgement}

This work is supported by the U.S. Department of Energy under Contract No. DE-EE0002762. Special thanks are due to Energy Modeling Group (EMG), Marathon Center of Excellence for Reservoir Studies (MCERS), and Unconventional Gas Institute (UNGI) at Colorado School of Mines and Foundation CMG.

\section{Nomenclature}

$\begin{array}{ll}a_{I} & \text { water activity of system } I \text {, dimensionless } \\ c & \text { compressibility, 1/psi } \\ C & \text { salt concentration, ppm } \\ D & \text { depth, } \mathrm{ft} \\ \mathrm{E}_{\mathrm{op}} & \text { osmotic efficiency, dimensionless } \\ D_{f / m} & \text { diffusion coefficient between fracture and matrix, } \mathrm{ft}^{2} / \mathrm{day} \\ k & \text { permeability, md } \\ p & \text { pressure, psi } \\ \hat{q} & \text { sink/source term, } 1 / \text { day } \\ R & \text { gas constant, equal to } 0.082 \mathrm{~atm} \cdot(\mathrm{mol} \cdot \mathrm{K})^{-1} \\ t & \text { time, day } \\ T & \text { temperature, } \mathrm{K} \\ V & \text { molar volume, } 1 / \mathrm{mol}\end{array}$




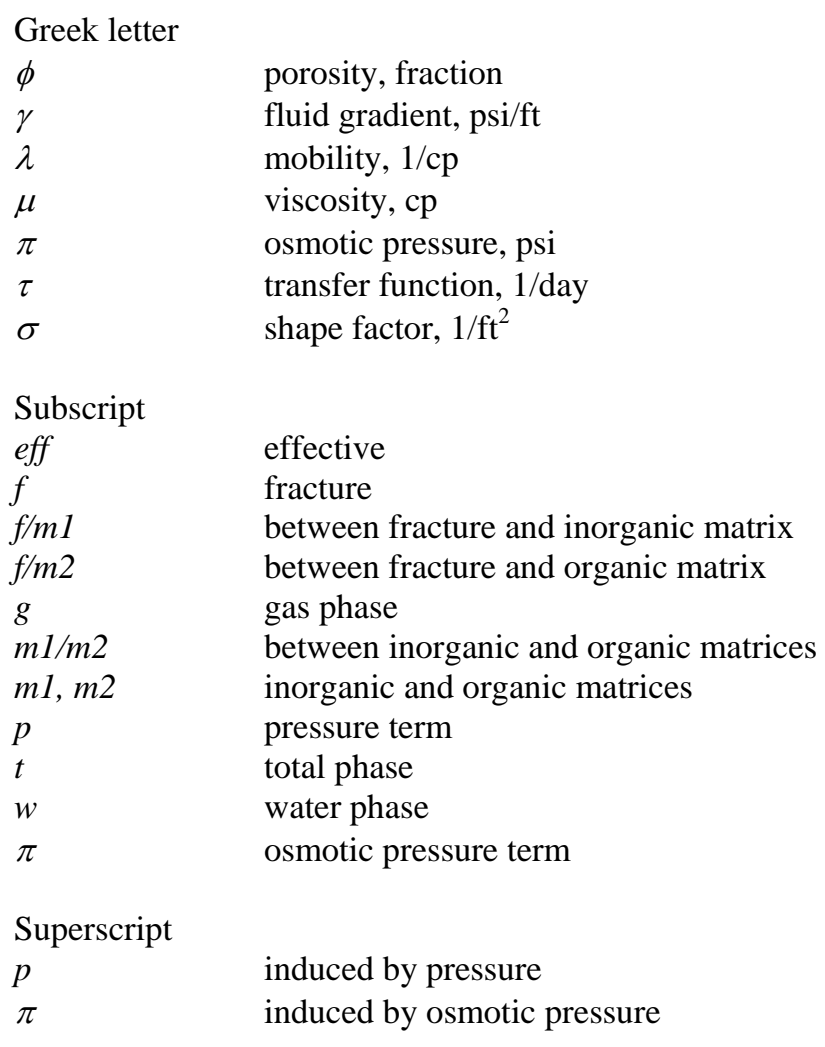

\section{References}

Al-Bazali, T. M., J. Zhang, M. E. Chenevert, and M. M. Sharma, 2006, "Factors Controlling the Membrane Efficiency of Shales When Interacting With Water-Based and Oil-Based Muds,” In International Oil \& Gas Conference and Exhibition in China. Beijing, China: Society of Petroleum Engineers.

Barry, T. H., R. K. Meyer, K. Yule, and J. Wittenberg, 2012, “A Case for Oil-Based Fracturing Fluids in Canadian Montney Unconventional Gas Development” In SPE Annual Technical Conference and Exhibition, San Antonio, Texas, USA: Society of Petroleum Engineers.

Bredehoeft, J. D., C. R. Blyth, W. A. White, and G. B. Maxey, 1963, "Possible Mechanism for Concentration of Brines in Subsurface Formations.” AAPG Bulletin 47, no. 2: pp. 257-269.

Charoenwongsa, S. 2012, "Numerical Simulation of The 3-D Hydraulic Fracturing Process, Clean up and Relevant Physics," $\mathrm{PhD}$, Colorado School of Mines.

Cheng, Y., 2012, "Impact of Water Dynamics in Fractures on the Performance of Hydraulically Fractured Wells in Gas-Shale Reservoirs.” Journal of Canadian Petroleum Technology 51, no. 2: pp. 143-151.

Economides, C. A., I. A. Ahmed, S. Apiwathanasorn, J. H. Lightner, B. Song, F. E. Vera Rosales, H. Xue, and Y. Zhang, 2012, "Stimulated Shale Volume Characterization: Multiwell Case Study from the Horn River Shale: II. Flow Perspective” In SPE Annual Technical Conference and Exhibition, San Antonio, Texas, USA: Society of Petroleum Engineers.

Haluszczak, L. O., A. W. Rose, and L. R. Kump, 2013, “Geochemical Evaluation of Flowback Brine from Marcellus Gas Wells in Pennsylvania, USA,” Applied Geochemistry 28: pp. 55-61.

Helgeson, H.C., D.H. Kirkham, G.C. Flowers, 1981, Theoretical prediction of the thermodynamic behavior of aqueous electrolytes by high pressures and temperatures; IV, Calculation of activity coefficients, osmotic coefficients, and apparent molal and standard and relative partial molal properties to 600 degrees C and 5kb, American Journal of Science 281, 1249-1516. 
Kazemi, H., S. Atan, M. Al-Matrook, J. Dreier, and E. Ozkan, 2005, “Multilevel Fracture Network Modeling of Naturally Fractured Reservoirs.” In SPE Reservoir Simulation Symposium, The Woodlands, Texas.

King, G. E., 2012, “Hydraulic Fracturing 101: What Every Representative, Environmentalist, Regulator, Reporter, Investor, University Researcher, Neighbor and Engineer Should Know About Estimating Frac Risk and Improving Frac Performance in Unconventional Gas and Oil Wells,” In SPE Hydraulic Fracturing Technology Conference. The Woodlands, Texas, USA: Society of Petroleum Engineers.

Lane, R., and A. Aderibigbe, 2013, “Rock/Fluid Chemistry Impacts on Shale Fracture Behavior,” In 2013 SPE International Symposium on Oilfield Chemistry, The Woodlands, TX, USA: Society of Petroleum Engineers.

Marine, I. W., and S. J. Fritz, 1981, “Osmotic Model to Explain Anomalous Hydraulic Heads,” Water Resources Research 17, no. 1: pp. 73-82.

Neuzil, C. E., and A. M. Provost, 2009, "Recent Experimental Data May Point to a Greater Role for Osmotic Pressures in the Subsurface,” Water Resources Research, 45, no. 3.

Neuzil, C. E, 2000, “Osmotic Generation of ‘anomalous’ Fluid Pressures in Geological Environments,” Nature, 403, no. 6766: pp. $182-184$.

Parmar, J., H. Dehghanpour and E. Kuru, 2013, "Drainage Against Gravity: Factors Impacting the Load Recovery in Fractures,” In SPE Unconventional Resources Conference, The Woodlands, TX, USA: Society of Petroleum Engineers.

Passey, Q. R., K. Bohacs, W. L. Esch, R. Klimentidis, and S. Sinha, 2010, "From Oil-Prone Source Rock to Gas-Producing Shale Reservoir - Geologic and Petrophysical Characterization of Unconventional Shale-Gas Reservoirs," In International Oil and Gas Conference and Exhibition in China. Beijing, China: Society of Petroleum Engineers.

Takeda, M., T. Hiratsuka, K. Ito, and S. Finsterle, 2012, Development and Application of Chemical Osmosis Simulator Based on TOUGH2, In 2012 TOUGH2 Symposium, Lawrence Berkeley National Laboratory, Berkeley, California, 2012.

Xu, T., N. Spycher, E. Sonnenthal, G. Zhang, L. Zheng, and K. Pruess, 2012, “TOUGHREACT User’s Guide: A Simulator Program for Non-isothermal Multiphase Reactive Transport in Variably Saturated Geological Media, Version 2.0.” 